\section{BIODIVERSITY AND ECOLOGY}

\section{Frosty fate}

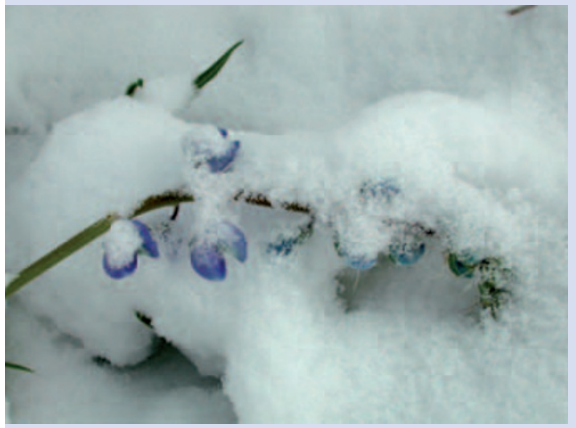

Ecology 89, 353-362 (2008)

Early snowmelt in the Rocky Mountains of the US is killing off the region's wildflowers, and scientists say the culprit is climate change. In recent decades, snow has begun to melt earlier in the season, warming the ground and leading to the premature arrival of leaf and flower buds. But the timing of spring frost events has remained fixed, and without the protective blanket of snow, delicate plant parts are left exposed.

David Inouye of the University of Maryland studied the onset of growth and subsequent frost damage to buds in three frost-sensitive species of perennial wildflower that bloom after the winter snowpack melts: subalpine larkspur, Aspen sunflower and Aspen fleabane. He found that an average of 36.1 percent of Aspen sunflower buds were frosted between 1992 and 1998, but that this shot to 73.9 percent in the 1999-2006 period. In only one year since 1998 did all plants escape frost damage.

If, owing to freezing temperatures, plants do not bud or early flowers are killed, the plant population can decline over time, warns the author. This could affect the entire ecosystem, from plant-specific seed-eating fruit flies to large mammals such as deer and elk that munch on wildflower blossoms.

Harvey Leifert

ENERGY

\section{Corn quandary}

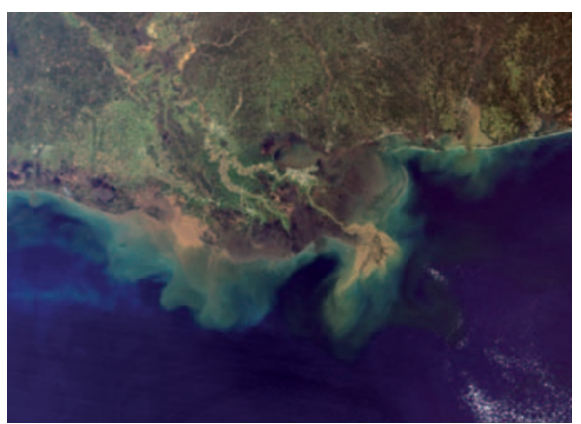

Proc. NatlAcad. Sci. USA 105, 4513-4518 (2008)

Efforts to reduce US greenhouse gas emissions by increasing the production of corn-based biofuels could contribute to an already worsening 'dead zone' in the Gulf of Mexico, finds a new study. Covering an area some 20,000 square kilometres most summers, the Gulf dead zone is characterized by low oxygen levels and is partly caused by nitrogen runoff from farms in the midwest.

Simon Donner of the University of British Columbia, Canada, and Christopher Kucharik of the University of Wisconsin used nutrient-cycling and land-use models to look at how growing more corn for ethanol production would alter nitrogen flow from the Mississippi and Atchafalaya Rivers into the Gulf. Their results suggest that a bill currently before the US Senate, which recommends producing 15 to 36 billion gallons of renewable fuels by 2022 , would boost nitrogen runoff by 10 to 34 percent.

This would jeopardize an existing goal of reducing the dead zone to less than 5,000 square kilometres to preserve Gulf coast fisheries. The researchers warn that reaching this target would require fewer, not more, nitrogen-heavy corn fields, which could be achieved only through a radical shift in the American diet and in agricultural land-use practices.

\section{Harvey Leifert}

\section{CLIMATE VARIABILITY \\ Hotter days ahead}

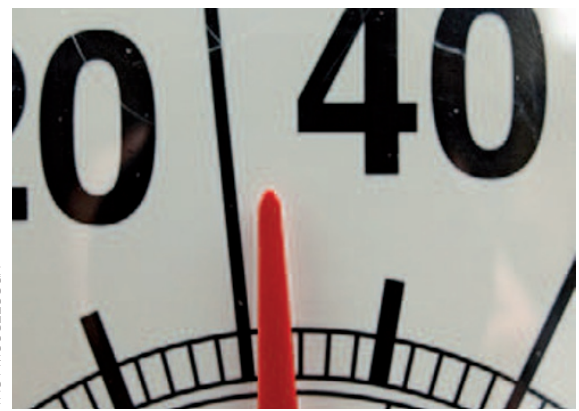

J. Geophys. Res. 113, D05115 (2008)

Global average temperatures have risen since the mid-twentieth century, yet temperature changes aren't always apparent in day-to-day weather variability. Now researchers have found that daily extremes may also be changing.

Simon Brown at the Met Office Hadley Centre, UK, and colleagues compiled daily temperature data from land-based sites throughout the world. They found warming of both the hottest and coldest daily temperatures since 1950 for most of Europe, Asia, Central and North America, and Australia, especially during northern winter and spring months. Daily minimum temperatures have seen the biggest increases, most notably over Russia and Canada, where the coldest days are now up to $4{ }^{\circ} \mathrm{C}$ warmer than they were mid-century.

There are some exceptions - for example, warm days and nights have cooled in eastern North America - but despite these atypical locales, in general the coldest temperatures are warming more rapidly than global mean temperatures. Ultimately, this means that climate change may be most obvious in the warmer winter nights and hotter summer days to come.

Alicia Newton

\section{ANTHROPOGENIC CHANGE}

\section{Deep disturbances}

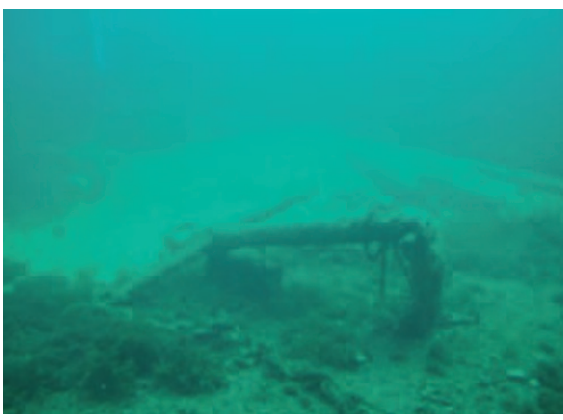

Geochem. Geophys. Geosys. 9, Q02012 (2008)

Engineered storage of carbon dioxide deep in the ocean has been suggested as a way of mitigating climate change, but some anthropogenic carbon dioxide has already begun to make its way to the ocean floor naturally. A new study finds that as carbon dioxide-rich surface water continues to sink over the coming centuries, the ocean floor will become an increasingly acidic and hostile habitat.

Marion Gehlen at the Laboratoire des Sciences du Climat et de l'Environnement, France, and colleagues used a combined global biogeochemical and sediment model to simulate the changes in deepsea chemistry that would occur with an increase in atmospheric carbon dioxide of one percent per year over the next 140 years. They found that the acidity of deep- 
sea water would rise steadily, with the most pronounced changes occurring in areas of deep-water formation, such as the North Atlantic.

Such changes could alter the composition of deep-sea communities. From tiny plankton to giant clams, many marine animals make their shells of calcium carbonate, which dissolves in acidic waters. The area of deep-sea floor favourable to these organisms could decrease by 58 percent, warn the researchers, who also predict a six percent decline in shell material preserved in the upper deep-sea sediment.

\section{Alicia Newton}

\section{OCEAN SCIENCE}

\section{Dammed sea rise}

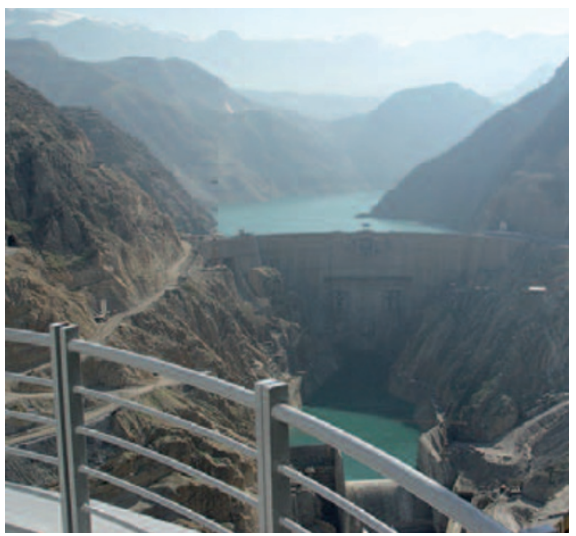

Science doi:10.1126/science.1154580 (2008)

By damming rivers, humans have masked the full extent of surging sea levels, a new study finds. Sea levels have risen by an average of 16 centimetres since 1930, and they would have risen by an additional three centimetres but for the water tucked away in manmade reservoirs last century, not carefully tallied until now.

Consulting a worldwide dam registry, Ben Chao and students from the National Central University, Taiwan, estimated the volume of water stored in 29,484 reservoirs built since 1900 . Measurements of sea-level rise have shown a variable rate of increase over the past 80 years. But by including the water stored year by year in dams, Chao's team revealed that sea level should, in fact, have risen steadily at a rate of 2.4 millimetres per year since 1930 . Without the dams and reservoirs, seas would have risen as rapidly from 1960 to 1990 as before and after, a point not previously recognized.

The latest report from the Intergovernmental Panel on Climate Change did not include the water behind dams when quantifying the various factors contributing to rising seas. These results suggest seas might creep up faster than expected, boding ill for future coastlines, especially with dam-building now largely halted by environmental concerns.

\section{Anna Barnett}

\section{MITIGATION}

\section{Iron findings}

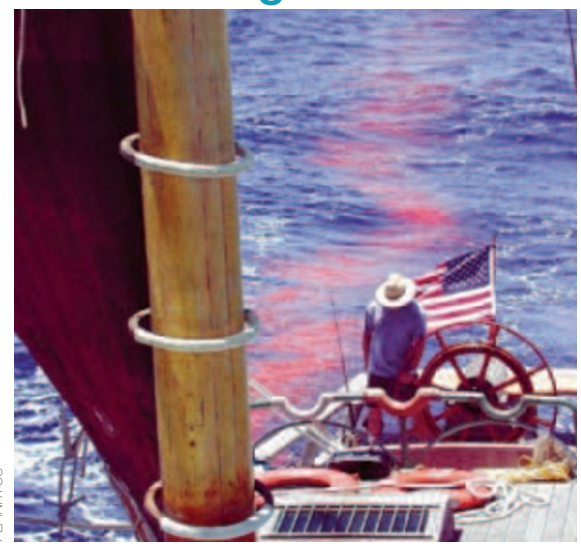

Global Biogeochem. Cycles 22, GB1023 (2008)

Seeding the ocean surface with iron could hold promise for storing carbon dioxide in the deep sea, suggests new research. The findings contrast with results from earlier studies that have questioned the validity of this geoengineering solution to climate change.

Stéphanie Jacquet at Vrije Universiteit Brussel, Belgium, and colleagues investigated the export of organic carbon to the deep sea during an artificial ironinduced phytoplankton bloom in the Southern Ocean in 2004. During the experiment, Jacquet's team measured particulate barium concentrations in the water column, which acted as an indicator of whether carbon was sinking or undergoing remineralization, the process by which marine organisms oxidize organic carbon to carbon dioxide. Only 12-14 percent of organic carbon was remineralized in the upper 1,000 metres of the water column, a smaller fraction than for comparable areas with natural algal blooms. The remaining organic matter sank, sometimes rapidly as large particles, into the deeper ocean.

The results suggest that fertilizing the ocean with iron could have potential for mitigating climate change. The researchers urge caution, however, in extrapolating the results to the entire Southern Ocean, as the study site was an eddy, which may have influenced the transport of carbon to the deep sea.

Alicia Newton

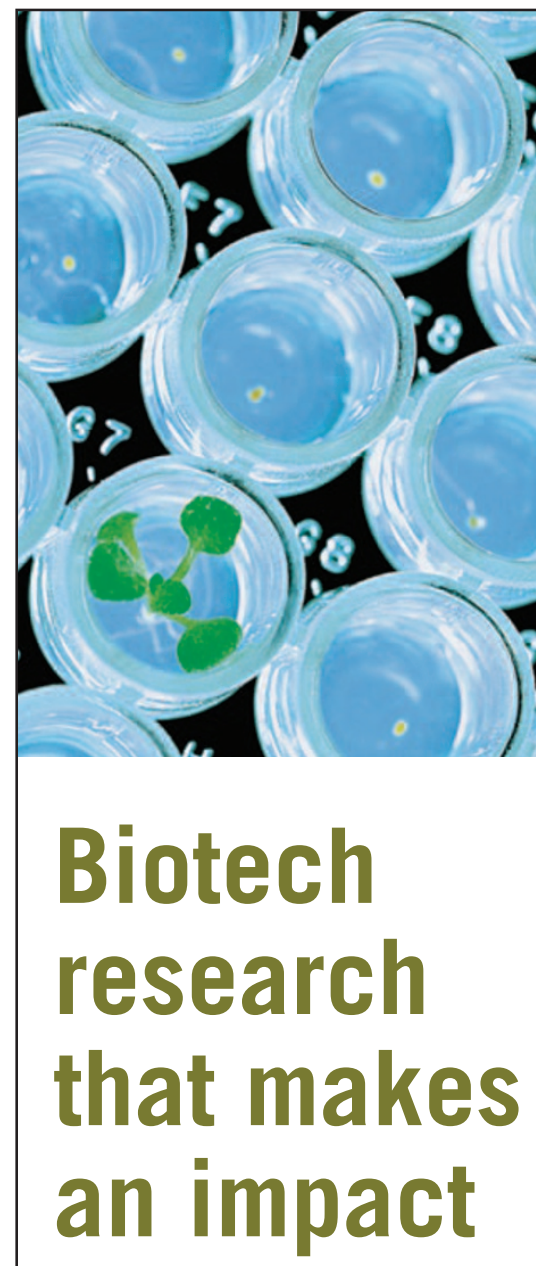

impact factor 22.672*

Nature Biotechnology is the source for today's most up-todate information on the science and business of biotechnology. Whether you are interested in biomedical technologies or agricultural, bioindustrial and environmental technologies, Nature Biotechnology brings you today's most significant research.

\section{For more information visit:} www.nature.com/ naturebiotechnology

*Journal Citation Reports, Thomson, 2007

\section{nature}

biotechnology 